\title{
Institutional Regulatory Mechanisms of Russian Labor Market in Economic Integration Conditions
}

\author{
Anna Mendel \\ Saratov Socio-Economic Institute, \\ Russian Economic University named after Plekhanov G.V., \\ 89, Radischeva Str., Saratov, 410003, Russia; \\ a-mendel@yandex.ru
}

Marina Yashina

Saratov Socio-Economic Institute,

Russian Economic University named after Plekhanov G.V., 89, Radischeva Str., Saratov, 410003, Russia; yashin@ssea.runnet.ru

\author{
Darya Smirnova \\ Povolzhsky Institute of Management named after P.A. \\ Stolypin, Russian Presidential Academy of National \\ Economy and Public Administration, \\ 23/25, Sobornaya Str., Saratov, 410031, Russian Fedration \\ darya.plyasunkov@mail.ru \\ Lenar Safiullin \\ Kazan Federal University \\ Institute of Management, Economics and Finance \\ Kazan, Russia
}

\begin{abstract}
The modern development of the Russian labor market is influenced by most of the geopolitical processes associated with the states integration into the economic union. The purpose is to create a general market, including the labor market that requires a thoughtful mechanism for institutional regulation of the Russian labor market based upon data on the shortage or excess of labor force. The research is based on the analysis and modeling methods as well as on the method of statistical information generalization. This article analyses Russian real as well as potential labor market capacity in the Eurasian economic integration conditions and deals with a methodology for calculating the indexes that has been developed by the authors. Labor market capacity is based on the supply and demand of the labor market. The national labor market capacity has two levels: potential and real. The real one is an aggregate number of employees which during the year are provided or will be provided by the current demand for labor at a certain level of wage. The potential capacity is the maximum possible level of demand for labor that reflects the needs of employers in the workforce based on its maximum possible consumption. The methodology for the calculating potential and real labor market capacity has been developed by the authors. Its result is the identified labor shortage in the country that allows one to form an idea about the institutional regulation of the Russian labor market in the Eurasian economic integration conditions. This idea is aimed at a three-level organization of social-labor relations (the international, supranational and national organizations).
\end{abstract}

Key words - labor market capacity, the real labor market capacity, the potential labor market capacity, the institutional regulation of the labor market, integration processes, the Eurasian Economic Union, migration policy.

\section{INTRODUCTION}

In the modern conditions, an effective Russian labor market development in the economic integration conditions in the post-Soviet space is possible only if a flexible and civilized labor market exists which formation depends upon the certain rules. They are determined by the relevant labor market institutions [1,p.3]. So the activation of economic integration processes between countries determines the significance of creating institutions for the regulation of the national labor market as the basis for its perfect functioning of each member countries of the integration union. Integration of Russia and partner countries into the Eurasian Economic Union (the EAEU) is a new stage in the development of external economic relations in the post-Soviet space. Today, the EAEU influences all spheres of Russian life, where the main place is given to the labor market.

The main goal of research is to determine the quantitative value demanded for knowledge formation about the nature and the degree of a country's dependency on the amount of required employees to create the institutional regulation system of the Russian labor market in the economic integration conditions.

\section{LITERATURE REVIEW}

During the last decades, the institutional regulation of the labor market is viewed by Russian and foreign researchers and economists. The most interesting investigations are made by A. Novak, John Kenneth Galbraith, Douglass Cecil North, John Thomas Dunlop, S.S. Vinokurov, V.A. Groshev, L.A. Mierin and others. The following authors as V. Leontev, F. Froebel, N.T. Vishnevskaia, S.V. Riazantsev, M.F. Tkachenko and others have devoted their researches to the analysis of the labor market formation according to globalization and economic integration. The issues of labor market capacity have been analyzed by S.B. Ashurov, S.V. Iudina and others.

At the moment, a clear definition of labor market capacity does not exist in Economics. 
The manual "Labor Economics and Socio-Labor Relations" discloses labor market capacity as a union of two points. They are a supply including the category of economically active employed people and an aggregate demand as economy needs labor force [4, p.126]. It should be mentioned that this definition is too extensive, and as it was mentioned above not only economically active employees can be regarded as a supply in the labor market.

There is no single opinion among researchers concerning the measurement of labor-market capacity. Some researchers suppose it can be determined by the required number of employees (Patlasov O.Iu. [5, p.138], Krylov A.O. [6, p.33]), the others measure it by the number of workplaces (Ashurov S.B. [7, p.104]). Both versions are worth existing because there are two levels of market capacity in science, they are potential and real. The real one will reflect the current situation of labor market and the potential level will show the labor need that is revealed through the aggregate demand.

S.V. Iudina defines labor market capacity as a difference between supply and demand [8, p.84]. Thus demand is a general number of vacancies and supply is a total number of unemployed people. This point of view, to our minds, is not actually correct as beyond total number of unemployed people having applied to the employment services there is a category of people (economically inactive) who want to work but they are not in the number of unemployed (such as pensioners and students). The labor market is a constantly changing dynamic system where people are divided into engaged ones and jobseekers. This category should be taken into account as a potential labor force in the number of economically inactive people.

There are two models of labor market regulation distinguished in the economic literature: neoclassical and institutional.

The first model examines the labor market by analogy with the commodity market, where the behavior of the employee and employer is determined by the logic of a rational individual, whose goal is to maximize results under the existing constraints.

However, in today's world, where the activation of economic integration processes between countries is intensifying, the most important condition for the normal functioning of the labor market of each member countries is the formation of institutions for regulating the national labor market.

Institutional theory studies the behavior of a particular person who pursues his own interests within the framework of maximizing utility and own well-being. But his behavior has several distinctive features, which include limited rationality and opportunism. Limited rationality is associated with the lack of reliable information and the costs of its search. Opportunism is associated with dishonest behavior of economic agents who are interested in their own gain.

D. North defines the concept of "institution" through a set of rules reflecting in formal norms and informal constraints and structuring interactions between people.
The institutional approach to the labor market study was determined by J. Dunlop. This approach was based on the analysis of professional and sectoral differences in the structure of the workforce and the corresponding levels of wages.

Labor market institutions are characterized by the fact that they are focused on regulating employment between the employee and the employer, storing and processing labor market information.

Formation of the institutional system regulation of the Russian labor market depends on the country socio-economic situation, which now is in the framework of innovative development. It should be noted that the importance of the human factor, as one of the most important elements necessary for building an innovative economy, should be recognized by the highest governing structures. Innovative development of the country involves the modernization of the entire economy. It is impossible to modernize the economy without changing the structure of production and creating new jobs.

Within the framework of Russia's participation in the Eurasian Economic Union, it will not enough to take in account only the national institutions that regulate the Russian labor market although the state as one of the regulatory institutions at the national level plays a primary role. The directions of the state policy will depend on the priorities of Russia's participation in the integration processes, therefore in the further analysis it is necessary to identify supranational institutions that will influence the national Russian labor market. At the same time, we should not forget that international institutions also have an influence on the supranational and national labor markets. Therefore, in the context of Russia's participation in economic integration processes, it is important to take into account the role of international, supranational and national institutions which regulate the national market by means of a set of management functions in order to make the balance between demand and supply.

\section{METHODS}

Characterizing the labor market situation in Russia in the Eurasian economic integration conditions, it is important to know how supply and demand are revealed. The labor demand is derived from the demand for final output and services and shows the variability of the labor relations system depending on changing economic conditions of the world economic space and on changing aggregate demand for output and services. The labor supply is derived from social factors related to the system of social relations in matters of labor, employment, wage level, the structure of specialties, motivational expectations and behavior of counterparts in the labor market, the economic activity of the labor force as well as the system of labor resources forming, the system of employees professional training, investments in professional education, the system of labor flows and labor migration.

The demand for the Russian labor market can be characterized by the total number of vacancies announced by an employer. It should be mentioned that the number of vacancies in the Russian labor market is below a sustainable 
growth rate (in 2012 - 1298 thousand vacancies, in 2014 1396 thousand vacancies). In 2015 the vacancies have fallen up to 1135 thousand; it is closely related to the economic crisis and as a result to great uncertainty among employers. At the end of 2016 the number of vacancies was increased up to $1,175,600$ [2, p.109].

Let us consider the supply in the labor market through the employed people and the number of jobseekers who applied to the employment services to go on job. The number of such jobseekers up to 2014 was decreasing: in 2011 they were about 5,363,000 people, in 2014 - about 4,046,000 people. An increase was up to $4,290,000$ people in 2015 . The number of employed people grew from 65,827,000 in 2011 up to $67,109,000$ in 2015 [3, p. 15]. Analyzing the facts, it is seen that the supply in the labor market is increasing, and it is obvious there are lots of people who are engaged and are going to work.

Let us observe labor market capacity to analyze the supply-demand ratio in Russia that demonstrates a fundamentally possible volume of labor consumption which is necessary for an effective socio-economic development of the whole state. Consequently, it influences an effectiveness of labor market development which means full employment including the natural unemployment rate.

\section{RESULTS}

The modern Russian labor market has its own features. It is double or even triple employment; full-time students, pensioners being economically inactive tend to work, are seeking for a job and get an employment; most of employed people are not satisfied by the current wage and as a result are looking for an opportunity to earn extra money. Employees are often sent on an unpaid leave, so on the one hand people are officially engaged but on the other hand they are to seek for an additional work. Besides, there is an illegal employment of migrant workers, seasonal jobs or temporary jobs on the basis of a civil law contract and an expansion of atypical employment forms in Russia. Analyzing all these features we can say that labor market capacity is forming out of aggregate demand taking all the economic needs in labor force and aggregate supply that covers all the economically active workforce including economically inactive people who would like to work.

Labor market capacity provides information about nature and the degree of a country's dependency on the amount of required employees. Therefore, the market capacity is characterized by the need for labor that significantly affects the labor markets structure of the EAEU countries [9, p.346]. Calculation of labor market capacity should be used to optimize supply and demand in the labor market as well as to make managerial decisions, to determine strategies for further development of the EAEU member countries, to develop an effective national migration policy and analyze the impact of the EAEU general labor market on the labor market in Russia and to form the institutional regulation system of the Russian labor market.

Let us analyze two levels of the national labor market capacity potential and real. The real one is an aggregate number of employees which during the year are provided or will be provided by the current demand for labor at a certain level of wage.

The potential capacity is the maximum possible level of demand for labor that reflects the needs of employers in the workforce based on its maximum possible consumption.

In such a way, the real capacity determines the supply provided by demand and the potential capacity determines the demand which means the amount of labor that has been acquired and can be acquired by employers.

Considering the Russian labor market capacity in the Eurasian economic integration conditions, it is important to mention that we are going to speak not about specific segments capacities, but about general real and potential capacity as a whole for the country.

Based on the essence of the labor market capacity, it is important for the state to ensure equality between the real and potential labor market capacity.

Let us construct a formula for finding the Russian real labor market capacity basing on the spoken above definition:

$$
\mathrm{X} \rho \varepsilon \alpha \lambda=\mathrm{E} \rho \mu+\varsigma / \Phi \lambda \mathrm{o} \alpha \delta
$$

$\mathrm{X} \rho \varepsilon \alpha \lambda$ - the Russian real labor market capacity, thousand people;

E $\rho \mu$ - employed people including residents as well as migrant workers, thousand people;

$\varsigma-$ a number of vacancies declared in the state employment services, thousand jobs;

$\Phi \lambda \mathrm{o} \alpha \delta$ - a load factor, which shows a number of workplaces occupied by one employee. This one is used by the authors and calculated as follows:

$$
\Phi \lambda \circ \alpha \delta=\Pi / \Omega
$$

$\Pi-$ a number of occupied workplaces, thousand workplaces;

$\Omega$ - an average annual number of workforce, thousand people.

The first formula characterizes a general amount of supplies in the Russian labor market, including those who have already employed and will be employed due to the availability of current demand. Being employed means to sign an employment contract between an employee (it may be a resident or a migrant worker) and a firm, a company or any other organization. This contract guarantees a wage that does not depend upon the income of the company where the person works. A load factor is a new one introduced by us which is necessary to determine the number of workplaces in Russia per an employee.

Let us define a formula for finding the Russian potential labor market capacity. As it is closely related to demand, it is important to take into account the factors which will affect the 
demand in the labor market capacity assessment. Some of them such as a general number of employed in economic and the number of vacancies claimed by state employment agencies are our calculation basis. Besides, there are some categories in Russia who have been employed but now they are classified as economically inactive population being a potential labor force. For instance, it may be the employee's retirement. Employers recruit new employees in exchange. According to the Russian Federal State Statistics Service (also known as Rosstat), potential employees are unemployed persons who are interested in getting a job for payment or profit, but the current conditions limit their active searching for work or their willing to start work [10]. They are students of employment age with a separation from work, people of agricultural jobs, a childcare category of people, unemployed pensioners and invalids, persons who do not have a job for a long time, who have stopped searching but ready to work etc.

So, it is logically to make a demand factor, which will be calculated on the basis of the ratio of the number of vacancies claimed by state employment agencies and people who applied there for employment. This factor is required to demonstrate the following fact: a part of potential labor force can be replaced at the workplace (for example, due to retirement) by an employee who has applied for a job to employment services.

We suppose that there is one more factor that influences an aggregate demand in the labor market. It reflects how many employees occupy one workplace. This is what we called earlier a load factor.

Thus, the calculating formula of the potential labor market capacity will be like this:

$$
\mathrm{X}_{\pi \mathrm{\tau} \tau}=\mathrm{N} * \Phi_{\varepsilon \chi . \alpha \chi \tau} * \Phi_{\varepsilon \mu \pi \lambda} * \Phi_{\lambda_{\mathrm{o} \alpha \delta}}+\Lambda_{\pi \mathrm{o} \tau} * \Phi_{\delta \varepsilon \mu}
$$

$\mathrm{X}_{\pi \mathrm{o \tau}}$ - the Russian potential labor market capacity, thousand workplaces;

\section{$\mathrm{N}$ - Number of people (population in Russia);}

$\Phi_{\varepsilon \chi . \alpha \chi \tau}-$ a factor (level) of people's economic activity which reflects a share of the economically active population in the total population of the country, thousand people;

$\Phi_{\varepsilon \mu \pi \lambda}$ - a factor of employment which reflects a share of employed people in economic out of the economically active population, thousand people;

$\Phi_{\lambda \circ \alpha \delta}-$ a load factor, which has been calculated according to formula 2 ;

$\Phi_{\delta \varepsilon \mu}-$ a demand factor which can be calculated:

Fdem $=$ V $/$ Urm

$\mathrm{V}$ - a number of vacancies declared in the state employment services, thousand jobs;

Urm - a number of unemployed people who applied to state employment agencies for employment out of residents and migrant workers, thousand people;

$\Lambda_{\pi \mathrm{o \tau}}-$ potential labor force, thousand people.
Let us calculate the real and potential Russia labor market capacity in the Eurasian economic integration conditions.

Let us define features of the real and potential ratio capacity of a labor market:

If there is Cpot $>$ Creal, then the number of vacancies (demand) exceeds the number of employees (supply). It means that the vacant places existing in the labor market of this socio-economic system are not maintained by employed people out of the workforce.

If there is Cpot < Creal, then it demonstrates the high unemployment rate and social tension as supply on the labor market exceeds its demand. At the same time, the larger the difference, the higher the unemployment rate and social tension in the country.

If there is Cpot $=$ Creal, then the entire population of the country is considered to be employed taking into account the natural unemployment rate.

\section{DISCUSSION}

Table 1 demonstrates the potential and real Russian labor market capacity.

TABLE I. THE POTENTIAL AND REAL RUSSIAN LABOR MARKET CAPACITY (IT HAS BEEN AUTHORED)

\begin{tabular}{|l|c|c|c|c|c|}
\hline \multicolumn{1}{|c|}{ Market Capacity } & $\mathbf{2 0 1 1}$ & $\mathbf{2 0 1 2}$ & $\mathbf{2 0 1 3}$ & $\mathbf{2 0 1 4}$ & $\mathbf{2 0 1 5}$ \\
\hline $\mathrm{C}_{\text {real }}$, thousand people & 66958,0 & 67864,4 & 67542,4 & 67751,9 & 68229,4 \\
\hline $\mathrm{C}_{\text {pot }}$, thousand workplaces & 74036,1 & 74882,3 & 74982,5 & 74531,3 & 74648,5 \\
\hline
\end{tabular}

The formulae results (1-3) have been calculated on the data put on the official websites of the Federal State Statistics Service.

The results of the made calculation (Table 1) prove the fact that the country requires labor force because the potential capacity exceeds the real capacity of the labor market during all the researched years. It suggests that Russia lacks a definite number of workplaces for the effective socio-economic development. However, using these formulae is possible only taking into account the specifics of various factors affecting the national labor market development. Summing up, the concept of the labor market capacity may be used only taking into account the national specifics of the labor market of the state. Naturally, nowadays, the workforce is demanded for the full-fledged functioning of the country's economy taking into account the employees qualifications, the education level and the involvement into the process of vacant job-replacing of various population groups. Today, the gap between the potential and real Russian labor market capacity is closely connected with the consequences of the economic crisis. In the future, the gap may be reduced taking the maximum benefit out of the Eurasian Economic Union (the implementation of the effective migration policy).

Thus, the analysis of all these facts allows us to form an idea about the institutional labor market regulation in Russia, based on the labor market capacity data. The institution in the Russian labor market should be understood as national 
institutions, which include organizations, services and standards that ensure its perfect functioning and contribute to the achievement of full employment and an effective migration policy.

The effective transition to the innovative economy is possible only with the creation and modernization of highperformance jobs. Ministry of Labor and Social Protection of the Russian Federation plans to create and modernize highperformance jobs in the amount of 25 million seats by 2020 .

Intellectualization of the economy and other branches of social life is the current trends in the development of society nowadays. This process has impact on the growing role of education and science, and at the same time the importance of intellectual activity within other sectors of the national economy is growing. Both of these tendencies lead to the formation and improvement of the educational, spiritual, scientific potential of the society, which is the basis of the country's socio-economic and innovative development. Objectivity of inclusion of the education system in the real sector of the economy was determined by global changes and ubiquitous digitization, which will require a new round of educational process reforms in Russia. The system of general and vocational education should contribute to the improvement of the quality of the workforce.

Since 2011, the Russian Federation has introduced a system of two-level higher professional education: bachelor's and master's degrees. The term of training under the bachelor's programs is four years; young people enter the labor market earlier. Today, it is necessary to take into account the trend of which specialties are demanded in the labor market. The process of education lasts more than one year, so it is important in the medium and long term to clearly define the demand for personnel at the level of the whole country.

Based on the current state of the Russian labor market, as well as the stage of development of Eurasian economic integration, the authors propose to consider as the key direction of employment development the increasing supply and demand for labor resources on the national labor market in the context of the impact of the institutional regulation system of the national labor market.

It is advisable to focus on the formation of such a system of public relations, which could ensure the maximum inclusion of labor resources in production processes and the realization of their labor potential. The given direction assumes rendering assistance in creation of workplaces due to development of enterprise sector, including small business and the social entrepreneurship, capable to form a favorable innovative and social climate.

The authors believe that it is necessary to reorient the taxation system, which will shift the tax burden from labor activity to other sources of taxation that have the least impact on employment and economic growth. It is necessary to remove barriers and constraints for economic entities in the national labor market.

The demand from the employer for labor resources will increase through providing support to business entities in the field of labor protection, which can be both consultative and investment. Modern employment policy should also be based on the priority of innovative development of the economy. Therefore, it is important to conduct targeted support to business entities that, by the nature of their activities and the state of infrastructure, are able to provide a scientific and technological breakthrough in critical directions for the country's economy.

The issue of increasing supply in the labor market, based on the law of supply and demand, is in the context of raising wages, improving working conditions and employment. At the same time, the imbalance in the labor market determines the need to find additional sources for filling the labor market, which was clarified through a quantitative indicator - the capacity of the national labor market. In this case, it is advisable to turn to labor migration from the countries of the Eurasian Economic Union.

To increase employment among the most vulnerable groups of the population, it is necessary to actively promote the social economy and stimulate the introduction of social innovations. In this regard, it is advisable to organize a single federal database system that will include information on the current labor market situation, as well as on specific vacancies and job seekers. The database should have a link to the information database on the migration processes of the EAEC.

\section{CONCLUSIONS}

The creation of a mechanism for regulating the Russian labor market by the institutional system within the framework of Eurasian economic integration is possible with the following identified conditions:

The creation of institutions for regulating the Russia labor market in the Eurasian integration conditions should occur not only at the national but also at the supranational and international organization levels of the social and labor relations.

The national labor market in the economic integration conditions is an open system that is influenced by many factors, both internal and external, from the Eurasian economic integration.

The vacant places existing in the labor market of the country are not maintained by employed people out of the workforce.

The situation in the national labor market can change throughout the year.

We should not forget that the labor market includes employed people out of the formal and informal sectors of the economy, undeclared vacancies and hidden unemployed.

The Russian labor market is functioning in conditions close to the labor force shortage (the growth of vacancies).

The people's activity in labor market (including migrant workers) depends on the wage of labor.

Consequently, the institutional system for regulating the national Russian labor market is a set of interrelated institutions that correspond to the special features of the 
international, supranational and national organization levels of social-labor relations, which affect supply and demand in the national labor market through a certain system of measures.

Thus, the article reveals the Russian potential and real labor market capacity, which quantitative results prove the country's need for labor. Based on the obtained data, the definition of the institutional system for regulating the Russian national labor market has been formulated. It should be mentioned that the creation of only national institutions for regulating the labor market in the economic integration conditions will not be enough. It is important to ensure the functioning of institutions both at the supranational level as well as at the international one that is an important issue for further research of the Russian labor market in the conditions of the EAEU development.

\section{References}

[1] M.G. Beliaeva, Institutional mechanisms for regulating employeeemployer relations: Doctoral dissertation Abstract: 08.00.01 / Beliaeva Marina Germanovna, Moscow, 2009.
[2] Russia in Figures, 2017, Rosstat, Moscow, 2017.

[3] Labor force, employment and unemployment in Russia (based on the results of sample labor force researches), 2016, Rosstat. Moscow, 2016

[4] Labor Economics and Socio-Labor Relations, Moscow. MSU, 1996.

[5] O.Iu. Patlasov, Theoretical marketing grounds for the national labor market regulation: Doctoral dissertation. 08.00.01, Tomsk, 2003.

[6] A.O. Krylov, The marketing research organization of the enterprise labor market and personnel. Dissertation: 08.00.05, Moscow, 2015.

[7] S.B. Ashurov, To the question of the potential workforce capacity, 2011, № 2, Vestnik RUDN University, p. 104-112.

[8] S.V. Iudina, Managing the labor market specialists in the southeast of the Republic of Tatarstan, Science Vector of Togliatti State University. Series: Economics and Management, 2013, № 4 (15), p. 84-88.

[9] D.S. Smirnova, The Russian labor market capacity in the economic integration conditions,Economics and Entrepreneurship, 2016, №8, p. 346-349.

[10] On approval of the Official Statistical Methodology for the formation of the work indicators system, employment and labor underutilization recommended by the 19th International Labor Statisticians Conference. $\begin{array}{lllll}\text { Rosstat order of } 31.12 .2015, & \text { № } 680 .\end{array}$ http://www.gks.ru/free_doc/new_site/population/trud/met-680.pdf (the application date 02.02 .2018 ) 